\title{
Meningococcaemia causing necrotizing cellulitis associated with acquired complement deficiency after gastric bypass surgery: a case report
}

Zoe Pletschette $^{1 *}$ (D), Elodie De Groote ${ }^{2}$, Wesley Mattheus ${ }^{3}$, Charlotte Waxweiler ${ }^{4}$, Jacques Creteur ${ }^{1}$ and David Grimaldi ${ }^{1}$

\begin{abstract}
Background: Neisseria meningitidis has rarely been described as an agent of necrotic soft tissue infection. Case presentation: We report a case of a septic shock with necrotizing cellulitis due to Neisseria meningitidis serogroup W, treated by urgent extensive surgical debridement followed by skin grafts. The invasive meningococcal disease occurred together with a complement deficiency, possibly acquired after bypass surgery that took place 1 year before.

Conclusions: Necrotic tissue infections should be considered part of the invasive meningococcal diseases spectrum and should prompt clinicians to look for complement deficiencies. Gastric bypass surgery associated malnutrition may be implicated but further verification is needed.
\end{abstract}

Keywords: Meningococcus; necrotizing fasciitis, Serogroup W, Case report

\section{Background}

Neisseria meningitidis are virulent bacteria known for causing fulminant purpura and purulent meningitis, but unusual presentations have been observed. We report here a rare case of necrotizing soft tissue infection (NSTI) related to meningococcaemia associated with a recently acquired complement deficiency.

\section{Case presentation}

In April 2019, a 50-year-old woman was admitted to our Intensive Care Unit for septic shock related to a necrotizing soft tissue infection.

\footnotetext{
* Correspondence: zoe.pletschette@erasme.ulb.ac.be

'Department of Intensive Care, Erasme Hospital, Université Libre de Bruxelles, 808 Route de Lennik, Brussels, Belgium

Full list of author information is available at the end of the article
}

Her medical history mentions a complicated bypass surgery 1 year before followed by severe malnutrition still in need of enteral feeding supplement. Earlier diagnoses include arterial hypertension and discoid lupus erythematosus. She never required immunosuppressive therapy.

A few hours before admission, the patient developed a sudden intense leg pain, associated with malaise. At the emergency room, she presented hyperaemia and swelling of both anterior thighs and right abdominal flank (Fig. 1a). Blood pressure was $50 / 35 \mathrm{mmHg}$, heart rate $140 \mathrm{bpm}$ and temperature $35.3^{\circ} \mathrm{C}$. Arterial blood lactate was $12 \mathrm{mmol} / \mathrm{L}(N<2 \mathrm{mmol} / \mathrm{L})$.

Intravenous fluids resuscitation was started with high doses of vasopressor (norepinephrine up to $6 \mathrm{mcg} / \mathrm{kg} /$ min) and empirical antimicrobial treatment combining piperacillin-tazobactam, amikacin and clindamycin. Septic shock was associated with severe disseminated 


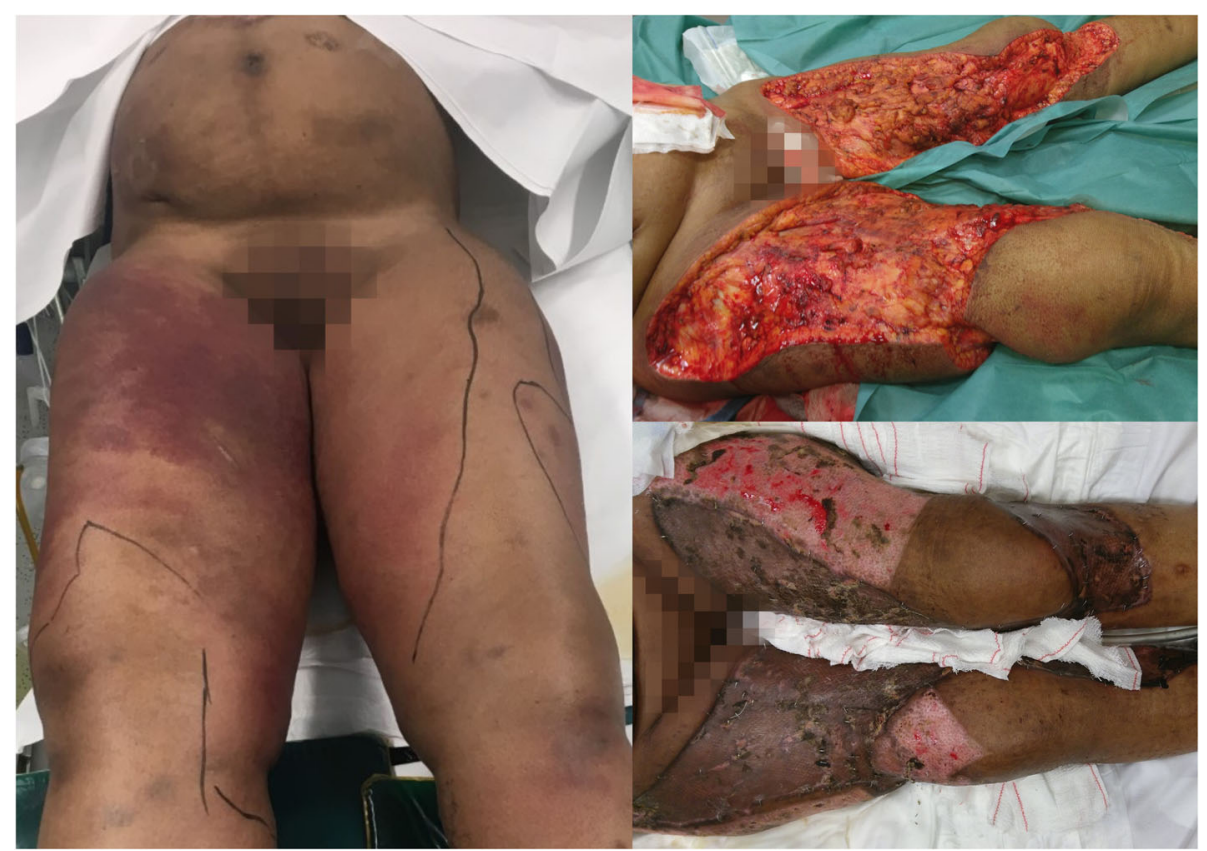

Fig. 1 Lower extremities lesions at admission (a), after debridement (b) and after skin grafting (c)

intravascular coagulation (prothrombin time $30 \mathrm{~s}$, activated platelet time superior to $150 \mathrm{~s}$, platelets 6000/ $\mathrm{mm} 3$, D -dimers $25,000 \mathrm{mcg} / \mathrm{L}$, fibrinogen $85 \mathrm{mg} / \mathrm{dL}$ ) and acute kidney injury (creatinine $2 \mathrm{mg} / \mathrm{dL}$, urea $96 \mathrm{mg} /$ $\mathrm{dL}$ and oliguria $20 \mathrm{~mL} /$ hour).

Urgent surgical exploration of the skin lesions revealed extensive subcutaneous necrosis not encompassing the fascia. The lesions underwent extensive debridement (Fig. 1b).

All surgical sample and blood cultures returned positive for Neisseria meningitidis. The first blood culture drawn at admission being so after $9 \mathrm{~h}$. The strain isolated was identified as a serogroup W subtype W: P1.5,2: F1-1: ST-11 (cc11). Genetic comparison based on Core Genome Multilocus Sequence Typing (cgMLST) using the international Neisseria public database for molecular typing (pubMLST) indicated that the isolate belonged to the UK 2013 lineage. The sequence has been deposited into the European Nucleotide Archive (ENA) database and is available under study accession number PRJEB37139.

Antibiotic treatment was de-escalated to benzylpenicillin related to a minimal inhibitory concentration (MIC) measured at $0,06 \mathrm{mg} / \mathrm{L}$.

A lumbar puncture performed at day 2 after coagulation correction returned normal values.

After 52 days spent in ICU with several complications occurring, the patient benefited from successful repair skin grafts (Fig. 1c) and was discharged to the hospital ward 10 days later.
Three months before this necrotizing cellulitis, the patient had undergone an immune status workup by a nephrologist for low-level proteinuria. ANA/ANCAs were negative, while $\mathrm{C} 3$ and total haemolytic activity (CH50) levels were low at 55 and 19\% respectively. A normal $\mathrm{C} 4$ level was found. Complement had been reported normal at the occasion of the earlier diagnostic investigation for discoid lupus erythematosus.

\section{Discussion and conclusion}

Numerous case reports identified Neisseria meningitidis as cause of severe cellulitis, more frequently involving the head and neck region [1-5].

Necrotic cellulitis differentiates from Purpura fulminans, which also leads to skin necrosis, but on the basis of confluent petechiae and as a result of endotoxinrelated microthrombi [6].

Previously published case reports of $N$. meningitidis related necrotizing soft tissue infections have been treated with extensive surgical debridement just as has been this patient $[7,8]$. Although necrosis did not extend beyond the fascia, early surgery in addition to prompt antibiotic treatment may have contributed to the patient's survival.

The meningococcal strain isolated, which belongs to the serogroup W of the genotype ST-11, is increasingly reported in many European countries with patients presenting abdominal symptoms in contrast to the more conventional presentation of meningococcal infections $[9,10]$. This particular ST-11 strain was described as 
epidemic in South America and then observed in 2009 in the UK and is therefore known as the South American/UK lineage. The original UK strain later evolved through further genetic rearrangements to become the UK 2013 strain [11]. This rising incidence led to the promotion of the ACWY vaccination rather than the MenC vaccination (recommended since July 2019 in Belgium).

Invasive meningococcal diseases (IMD) are favoured by complement deficiencies. Inherited deficiencies involving alternate pathway (C3 [12], factor $\mathrm{D}$, properdin [13]), or terminal pathway components (C5 through C9) [14-16] are well-described risk factors for IMD in childhood [17].

Acquired deficiency in $\mathrm{C} 5$, induced by the therapeutic monoclonal antibody eculizumab (an inhibitor of C5 cleavage), has also been shown to favour IMD [18].

Hypocomplementemia can be due to immune complex formation in antibody-mediated immune diseases such as cryoglobulinemia, systemic lupus erythematosus and endocarditis. However, to our knowledge, this phenomenon has not been linked to an increased susceptibility to IMD [17].

In our case, the $\mathrm{CH} 50$ and the $\mathrm{C} 3$ were abnormally low 3 months before the IMD though normal several years earlier. We hypothesize that the complement deficiency was acquired following the complicated gastric bypass surgery. This is suggested by the study of Gómez-Abril et al. [19] whose systematic exploration of immunological and laboratory abnormalities following bypass surgery demonstrated low levels of $\mathrm{C} 3$.

While vaccination against $N$. meningitidis in complement deficient persons is widely recommended [20], it is not clear at this stage how frequent hypocomplementemia is to be found after gastric bypass surgery since our case is likely the first one described. Vaccination of such patients could be offered broadly once complement deficiencies is demonstrated regularly.

In conclusion, we report a rare case of $N$. meningitidis related necrotizing cellulitis, an entity different from fulminant purpura. Meningococcemia was possibly favoured by an acquired classical pathway complement deficiency following a complicated gastric bypass entailing severe malnutrition.

Neisseria meningitidis should be considered among the causes of necrotizing cellulitis. Whether gastric bypass surgery associated malnutrition impairs complement function deserves further confirmation.

\footnotetext{
Abbreviations

NSTI: Necrotizing soft tissue infection; cgMLST: Core genome multilocus sequence typing; pubMLST: Public multilocus sequence typing; ENA: European Nucleotide Archive; MenC: Meningococcal C vaccine; MenACWY: Meningococcal ACWY vaccine; UK: United Kingdom; MIC: Minimal inhibitory concentration; ICU: Intensive Care Unit; ANA: Antinuclear antibody; ANCA: Anti-neutrophil cytoplasmic antibody; IMD: Invasive meningococcal diseases; MBL: Mannan-binding lectin
}

\section{Acknowledgements}

Not applicable.

\section{Authors' contributions}

$E D, C W, Z P, D G, J C$ treated the patient. MW performed the genetic analysis of the strain. ZP and DG wrote the manuscript draft, all the authors approved the final version of the manuscript.

\section{Funding}

This research received no specific grant from any funding agency in the public, commercial, or not-for-profit sector.

\section{Availability of data and materials}

All data generated or analyzed during this study are included in this published article.

Ethics approval and consent to participate Not applicable.

\section{Consent for publication}

The patient gave written consent for their personal or clinical details along with any identifying images to be published in this study.

\section{Competing interests}

The authors declare that they have no competing interests.

\section{Author details}

'Department of Intensive Care, Erasme Hospital, Université Libre de Bruxelles, 808 Route de Lennik, Brussels, Belgium. ${ }^{2}$ Department of Infectious Diseases, Erasme Hospital, Université Libre de Bruxelles, Brussels, Belgium.

${ }^{3}$ Meningococcal Reference Centre, Sciensano, Brussels, Belgium. ${ }^{4}$ Department of Plastic Surgery, Erasme Hospital, Université Libre de Bruxelles, Brussels, Belgium.

Received: 10 December 2019 Accepted: 11 May 2020

Published online: 20 May 2020

\section{References}

1. Carrascosa MF, Casuso-Sáenz E, Salcines-Caviedes JR. Neisseria meningitidis cellulitis. Int J Infect Dis. 2012;16(10):e760.

2. Ozaki B, Kittai A, Chang S. Neisseria meningitidis as a cause of facial cellulitis. BMJ Case Rep. 2014. https://doi.org/10.1136/bcr-2014- 203774.

3. Yip KP, Wales E. Meningococcal cellulitis: an unusual presentation in the elderly. Eur Geriatr Med. 2015;6(6):591-2.

4. Chand DV. First reported case of Neisseria meningitidis Periorbital cellulitis associated with meningitis. PEDIATRICS. 2005;116(6):e874-5.

5. Cartolano G-L, Barbier C, Arnoult L, Simon D, Ricome J-L, Hayon J. Fatal acute cellulitis due to Neisseria meningitidis. J Clin Microbiol. 2003:41(8): 3996-7.

6. Prieto-Granada CN, Lobo AZ, Mihm MC Jr. Skin infections. In: Kradin RL, editor. Diagnostic Pathology of Infectious Disease. Philadelphia: Elsevier; 2018. p. 542-7.

7. Moris V, Chapuis A, Guillier D, Jeudy G, Huther M, Auffret N, et al. Necrotizing fasciitis caused by genogroup $\times$ Neisseria meningitidis. QJM Int J Med. 2017:110(9):589-90.

8. Russcher A, Fanoy E, van Olden GDJ, Graafland AD, van der Ende A, Knol MJ. Necrotising fasciitis as atypical presentation of infection with emerging Neisseria meningitidis serogroup W (MenW) clonal complex 11, the Netherlands, march 2017. Eurosurveillance. 2017:22(23):30549.

9. Abad R, Vázquez JA. Early evidence of expanding W ST-11 CC meningococcal incidence in Spain. J Inf Secur. 2016;73(3):296-7.

10. Lucidarme J, Scott KJ, Ure R, Smith A, Lindsay D, Stenmark B, et al. An international invasive meningococcal disease outbreak due to a novel andrapidly expanding serogroup W strain, Scotland and Sweden, July to August 2015. Eurosurveillance. 2016;21 (45):15-23.

11. Booy R, Gentile A, Nissen M, Whelan J, Abitbol V. Recent changes in the epidemiology of Neisseria meningitidis serogroup W across the world, current vaccination policy choices and possible future strategies. Hum Vaccines Immunother. 2019;15(2):470-80. 
12. S Reis E, Falcão DA, Isaac L. Clinical aspects and molecular basis of primary deficiencies of complement component $\mathrm{C} 3$ and its regulatory proteins factor I and factor H. Scand J Immunol. 2006;63(3):155-68.

13. Densen $P$, Weiler JM, Griffiss JM, Hoffmann LG. Familial properdin deficiency and fatal meningococcemia. Correction of the bactericidal defect by vaccination. N Engl J Med. 1987;316(15):922-6.

14. Arnaout R, Al Shorbaghi S, Al Dhekri H, Al-Mousa H, Al Ghonaium A, Al Saud B, et al. C5 complement deficiency in a Saudi family, molecular characterization of mutation and literature review. J Clin Immunol. 2013; 33(4):871-5.

15. Nagata M, Hara T, Aoki T, Mizuno Y, Akeda H, Inaba S, et al. Inherited deficiency of ninth component of complement: an increased risk of meningococcal meningitis. J Pediatr. 1989:114(2):260-4.

16. Sanal O, Loos M, Ersoy F, Kanra G, Seçmeer G, Tezcan I. Complement component deficiencies and infection: $\mathrm{C} 5, \mathrm{C} 8$ and $\mathrm{C} 3$ deficiencies in three families. Eur J Pediatr. 1992;151(9):676-9.

17. Lewis LA, Ram S. Meningococcal disease and the complement system. Virulence. 2014;5(1):98-126

18. McNamara LA, Topaz N, Wang X, Hariri S, Fox L, MacNeil JR. High risk for invasive meningococcal disease among patients receiving Eculizumab (Soliris) despite receipt of meningococcal vaccine. MMWR Morb Mortal Wkly Rep. 2017:66(27):734-7.

19. Gómez-Abril SÁ, Morillas-Ariño C, Ponce-Marco JL, Torres-Sánchez T, Delgado-Gomis F, Hernández-Mijares A, et al. Short- and long-term effects of weight loss on the complement component C3 after laparoscopic gastric bypass in obese patients. Obes Surg. 2016;26(11):2756-63.

20. Cohn AC, MacNeil JR, Clark TA, Ortega-Sanchez IR, Briere EZ, Meissner HC, et al. Prevention and control of meningococcal disease: recommendations of the Advisory Committee on Immunization Practices (ACIP). MMWR Recomm Rep Morb Mortal Wkly Rep Recomm Rep. 2013;62(RR-2):1-28

\section{Publisher's Note}

Springer Nature remains neutral with regard to jurisdictional claims in published maps and institutional affiliations.

Ready to submit your research? Choose BMC and benefit from:

- fast, convenient online submission

- thorough peer review by experienced researchers in your field

- rapid publication on acceptance

- support for research data, including large and complex data types

- gold Open Access which fosters wider collaboration and increased citations

- maximum visibility for your research: over $100 \mathrm{M}$ website views per year

At $\mathrm{BMC}$, research is always in progress.

Learn more biomedcentral.com/submissions 